\title{
Variants of SARS-COV-2 and the Death Toll
}

\author{
Takesi Saito* \\ Department of Physics, Kwansei Gakuin University, Sanda 669-1337, Japan \\ *tsaito@ k7.dion.ne.jp
}

\begin{abstract}
New variants of SARS-COV-2 have been found in various countries. Especially, the UK has been attacked by India's Delta Plus, and the spread of infection has been very rapid, since it is extremely infectious. Fortunately, however, the number of deaths has been stayed flat, where deaths are reported to be those who are not yet received a shot of COVID-19 vaccine. In this short not, we would like to consider why the number of deaths is so small, compared with high cases, around the infection peak, when the basic reproduction number is very large.
\end{abstract}

\section{Formulation and Discussion}

We consider this problem by means of the SIR model [1], [2 13] in the theory of infection. Equations of the SIR model are given by

$$
\begin{aligned}
& \mathrm{dS} / \mathrm{dt}=-\alpha \mathrm{SI}, \\
& \mathrm{dI} / \mathrm{dt}=(\alpha \mathrm{S}-1) \mathrm{I}, \\
& \mathrm{dR} / \mathrm{dt}=\mathrm{I},
\end{aligned}
$$

where S, I and R are numbers for susceptibles, infectives and removed, respectively, and $\alpha$ is the basic reproduction number. The removed ratio $\mathrm{c}$ is set to be $\mathrm{c}=1$ for simplicity. We normalize $\mathrm{S}$, I and $\mathrm{R}$ as

$$
\mathrm{S}+\mathrm{I}+\mathrm{R}=1
$$

At the peak of infection $\mathrm{t}=\mathrm{T}$, following formulas are well known to hold

$$
\begin{aligned}
& \mathrm{S}(\mathrm{T})=1 / \alpha, \\
& \mathrm{R}(\mathrm{T})=(\ln \alpha) / \alpha, \\
& \mathrm{I}(\mathrm{T})=1-(1 / \alpha)-(\ln \alpha) / \alpha .
\end{aligned}
$$

NOTE: This preprint reports new research that has not been certified by peer review and should not be used to guide clinical practice. 
medRxiv preprint doi: https://doi.org/10.1101/2021.07.08.21260081; this version posted July 16, 2021. The copyright holder has placed this preprint (which was not certified by peer review) in the Public Domain. It is no longer restricted by copyright. Anyone can legally share, reuse, remix, or adapt this material for any purpose without crediting the original authors.

Curves of $\mathrm{R}(\mathrm{T})$ and $\mathrm{I}(\mathrm{T})$ against $\alpha$ are drawn in Fig. 1. From Fig. 1 we see that the larger $\mathrm{I}(\mathrm{T})$, then the smaller $\mathrm{R}(\mathrm{T})$ for $\alpha \geq 3.51$ at the peak. That is to say, at the peak the removed number decreases as the infection number increases for $\alpha \geq 3.51$. For $\alpha=5$, as an example of higher cases, we see that $\mathrm{I}(\mathrm{T})=0.48$ is larger than $\mathrm{R}(\mathrm{T})=0.32$. Conversely, for $\alpha=2.5$, as an example of lower cases, we get $\mathrm{I}(\mathrm{T})=0.26$ is smaller than $\mathrm{R}(\mathrm{T})=0.37$. Once having $\alpha=5$ and 2.5, we can draw curves for S, I and R against the time t by means of Excell in Figs. 2 and 3, respectively. In Fig. 2 one can see that the peak value I(T) is correctly lager than $\mathrm{R}(\mathrm{T})$, while in Fig. 3 this relationship is reversely.

Let us define the morality ratio by $\lambda=\mathrm{D}(\mathrm{t}) / \mathrm{R}(\mathrm{t})$, where $\mathrm{D}(\mathrm{t})$ is the accumulated number of deaths at t. We assume $\lambda$ to be approximately constant $[14]$. Hence $D(t)$ is proportional to $\mathrm{R}(\mathrm{t})$. Our aim is to consider the reason why the number of deaths is so small as compared with that of high cases at the peak, $\mathrm{t}=\mathrm{T}$, when $\alpha$ is very large. From above discussions, we conclude that as $\alpha$ gets bigger, $\mathrm{I}(\mathrm{T})$ increases, then $\mathrm{R}(\mathrm{T})$ decreases inversely, hence $\mathrm{D}(\mathrm{T})=$ $\lambda \mathrm{R}(\mathrm{T})$ does also so.

After passing the peak, we get $\mathrm{R}(\mathrm{t})>I(t)$, as is seen in Fig. 2 with $\alpha=5$. However, from the formula $\mathrm{D}(\infty)=\lambda \mathrm{R}(\infty) \cong \lambda$, there is a possibility that the accumulate number $\mathrm{D}(\infty)$ at the end may be still small, when $\lambda$ is very small. Otherwise, of course, $\mathrm{D}(\infty)$ may be large.

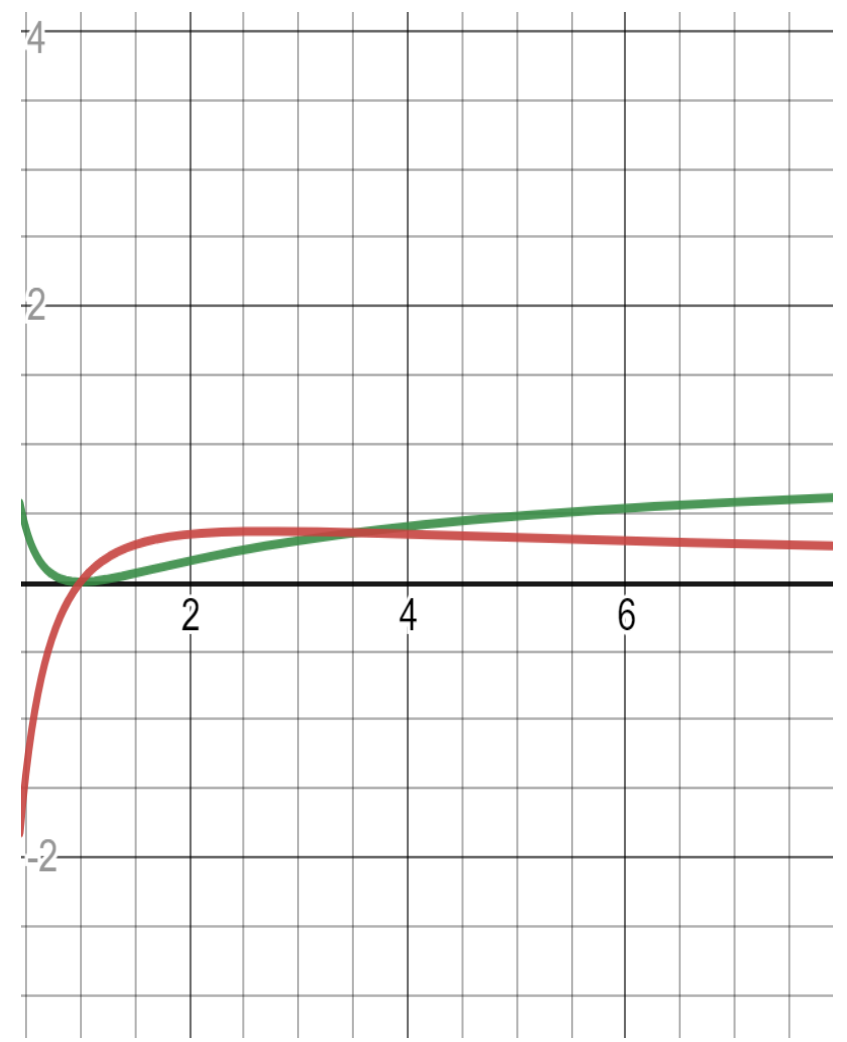


medRxiv preprint doi: https://doi.org/10.1101/2021.07.08.21260081; this version posted July 16, 2021. The copyright holder has placed this preprint (which was not certified by peer review) in the Public Domain. It is no longer restricted by copyright. Anyone can legally share, reuse, remix, or adapt this material for any purpose without crediting the original authors.

Fig1. The red curve is for $\mathrm{R}(\mathrm{T})=(\ln \alpha) / \alpha$. The blue curve is for $\mathrm{I}(\mathrm{T})=1-(1 / \alpha)-(\ln \alpha) / \alpha$. The horizontal line corresponds to $\alpha \geq 1$. The crossing point for both curves is $\alpha=3.51$.

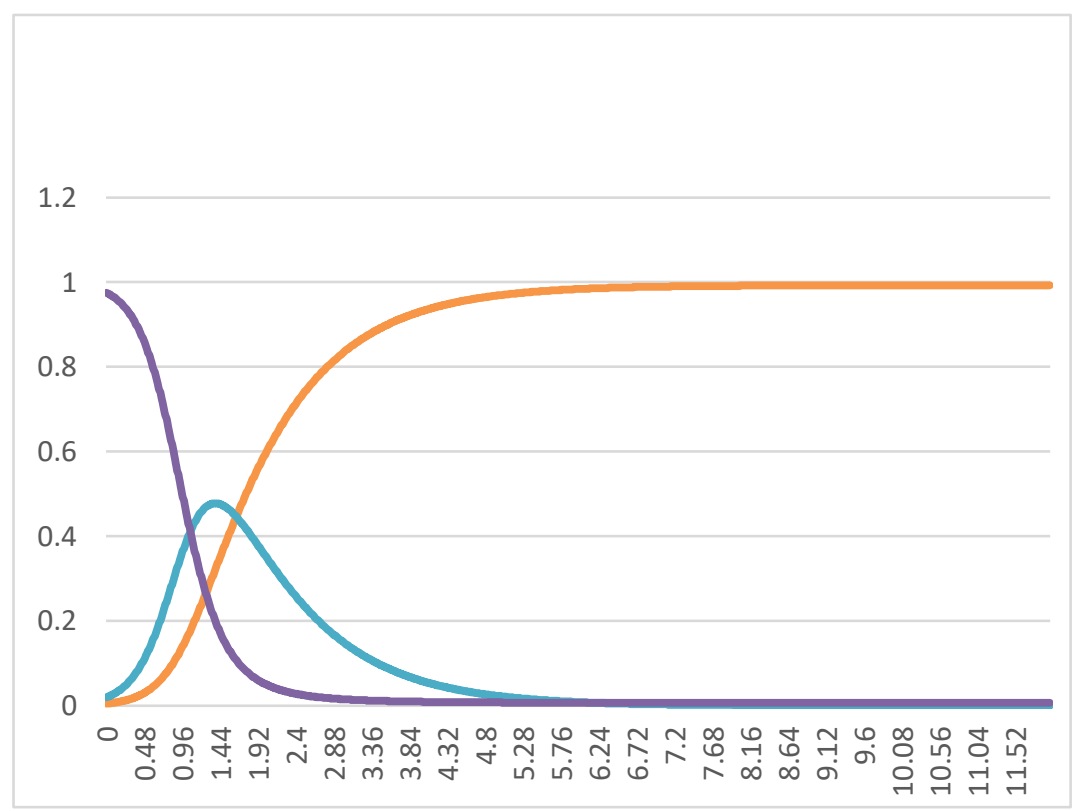

Fig. 2. Curves for $\mathrm{S}$ (deep-blue), I(blue) and $\mathrm{R}($ red) with $\alpha=5, \mathrm{c}=1$, where $\mathrm{S}$, I and $\mathrm{R}$ are numbers for susceptibles, infectives and removed, respectively, and $\alpha$ is the basic reproduction number, c the removed ratio. The vertical line corresponds to $\mathrm{S}$, I and $\mathrm{R}$. The horizontal line corresponds to a time.

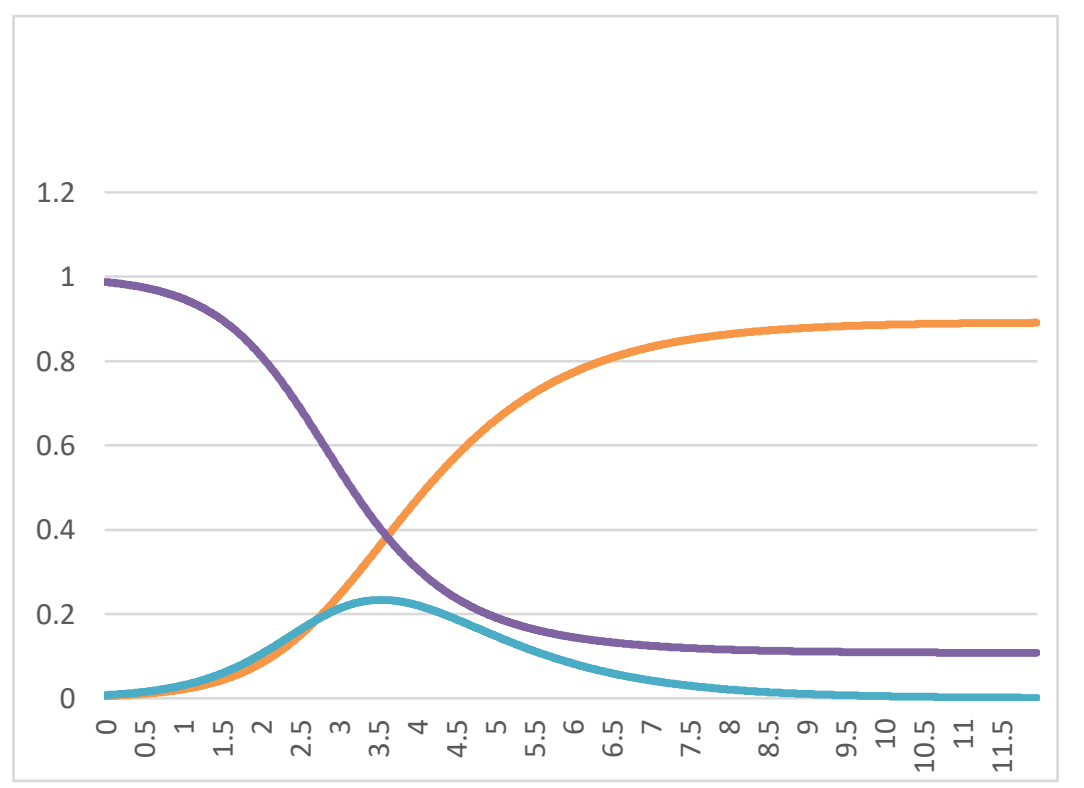

Fig. 3. Curves for $\mathrm{S}$ (deep-blue), I(blue) and R(red) with $\alpha=2.5, c=1$. 
medRxiv preprint doi: https://doi.org/10.1101/2021.07.08.21260081; this version posted July 16, 2021. The copyright holder has placed this

\section{Conclusion}

In conclusion, we succeeded to explain why the number of deaths is so small, compared with high cases, at the infectious peak, when the basic reproduction $\alpha$ is very large. This essentially comes from Eqs.(6) and (7) derived from the SIR equation. The larger the basic reproduction number $\alpha$, the larger the infectious number $\mathrm{I}(\mathrm{T})$. The larger the infectious number $\mathrm{I}(\mathrm{T})$, then the smaller the removed number $\mathrm{R}(\mathrm{T})$, hence the smaller the death toll $\mathrm{D}(\mathrm{T})$, around the infectious peak.

After passing the peak, we get $\mathrm{R}(\mathrm{t})>I(t)$, as is seen in Fig. 2 with $\alpha=5$. However, from the formula $\mathrm{D}(\infty)=\lambda \mathrm{R}(\infty) \cong \lambda$, there is a possibility that the accumulate number $\mathrm{D}(\infty)$ at the end may be still small, when $\lambda$ is very small. Otherwise, of course, $\mathrm{D}(\infty)$ may be large.

\section{Acknowledgment}

The author would like to express his deep gratitude to K. Shigemoto for valuable discussions.

\section{References}

[1] W. O. Kermack and A.G. McKendrick, "A Contribution to the Mathematical Theory of Epidemics”, Proceedings of the Royal Society A115 , 700-721 (1927).

[2[ 1.O. Diekmann, J. A. P. Heesterbeak and J. A. J. Metz (1990), On the definition and the computation of the basic reproduction ratio in models for infectious diseases in heterogeneous populations, J. Math. Biol. 28: 365-382.

[3] W. D. Murray, "Epidemic models and the dynamics of infectious diseases", Mathematical Biology 42, 610-650 (1993).

[4] H. Hethcote, ”The Mathematics of Infectious Diseases”, SIAM Review 42, 599-653 (2000).

[5] M.J. Keeling and L. Danon, "Mathematical modelling of infectious diseases ", British Medical Bulletin 92, 33-42 (2009).

[6] S. Pathak, A. Maiti and G.P. Samanta, "Rich dynamics of an SIR epidemic model", Nonlinear Analysis: Modelling and Control 15, 71-81 (2010).

[7] T. Harko, F.S.N. Lobo, M.K. Mak, "Exact analytical solutions of the Susceptible Infected-Recovered (SIR) epidemic model and of the SIR model with equal death and birth rates", Applied Mathematics and Computation 236, 184194 (2014).

[8J.C. Miller, "Mathematical models of SIR disease spread with combined non-sexual and sexual transmission routes”, Infectious Disease Modelling 2, 3555 (2017). 
medRxiv preprint doi: https://doi.org/10.1101/2021.07.08.21260081; this version posted July 16, 2021. The copyright holder has placed this preprint (which was not certified by peer review) in the Public Domain. It is no longer restricted by copyright. Anyone can legally share, reuse, remix, or adapt this material for any purpose without crediting the original authors.

[9] R. Sameni, "Mathematical Modeling of Epidemic Diseases; A Case Study of the COVID-19 Coronavirus", [arXiv:2003.11371 [q-bio.PE]](2017).

[10] T. Kuniya (2020), Prediction of the epidemic peak of coronavirus dis-ease in Japan, 2020, Journal of Clinical Medicine 9: 789.

[11] T. Kuniya (2020), Evaluation of the effect of the state of emergency for the first wave of COVID-19 in Japan, Infectious Disease Modelling 5: 580-587.

[12] T. Saito and K. Shigemoto, "A Logistic Curve in the SIR Model and Its Application to Deaths by COVID-19 in Japan ”, [medRxiv 10.1101/2020.06.25.20139865](2020).

[13] A. Kokado and T. Saito, "A Logistic Formula in Biology and Its Application to COVID19 in Japan”, [medRxiv 2021.03.24, 21254279](2021).

[14] Data published from the Ministry of Health, Labor and Welfare of Japan. See for example, "Summary of the New Coronavirus Infection "(in Japanese), https://hazard.yahoo.co.jp/article/20200207; "Status of the Domestic New Coronavirus Infection"(in Japanese), https://toyokeizai.net/sp/visual/tko/covid19/. 